\title{
PERBEDAAN PENGARUH LATIHAN HANDSTAND PUSH-UP DAN FLOOR PUSH-UP TERHADAP DAYA TAHAN OTOT LENGAN ATLET GULAT PUTRA JAWA TENGAH TAHUN 2020
}

\author{
Ade Mulyono ${ }^{a}$, Rima Febrianti, M.Pd. ${ }^{b}$, Satrio Sakti Rumpoko, S.Pd., M.Or., ${ }^{c}$ \\ abc Physical Education, Universitas Tunas Pembangunan Surakarta, Surakarta, Indonesia. \\ email:a ademulyo16@gmail.com
}

I N F O A R T I K E L

Sejarah artikel:

Menerima 1Juli 2021

Revisi 21 Juli 2021

Diterima 22

Online 30 Juli 2021

\section{Kata kunci:}

Daya tahan Otot Lengan, Handstand \& Floor Push-up, Gulat

\section{Keywords:}

Arm Muscle

Endurance, Handstand $\mathcal{E}$ Floor Push-ups, Wrestling
Style APA dalam mensitasi artikel ini: [Heading sitasi]

Ade Mulyono. (2020). Perbedaan pengaruh latihan handstand push-up dan floor push-up terhadap daya tahan otot lengan atlet gulat putra jawa tengah tahun 2020. Jurnal Ilmiah Penjas ( Volume 7. No 2) (35-46)

\section{ABSTRAK}

Penelitian ini bertujuan untuk melihat perbedaan peningkatan daya tahan otot lengan melalui metode latihan Handstand Push-up dan Floor Push-up pada atlet gulat Provinsi Jawa Tengah Tahun 2020 di Klub Gulat Han Academy Solo. Penelitian ini dilaksanakan menggunakan deskripsi kuantitatif dan menggunakan "Two group pretest-posttest design". Subyek penelitian ini adalah atlet gulat putra Provinsi Jawa Tengah yang berlatih di Klub Han Academy Solo yang berjumlah 30 atlet, yang terdiri dari 15 atlet treatment Handstand Push-up dan 15 atlet treatment Floor Push-up. Sumber data dalam penelitian ini berasal dari 30 atlet. Teknik pengumpulan data adalah melalui push-up test untuk mengukur daya tahan otot lengan. Analisis data menggunakan uji statistik nonparametrik wilcoxon. Hasil analisis data dapat disampaikan sebagai berikut: Hasil pengujian peningkaan untuk Handstand Push-up diperoleh peningkatan dari 46,46 menjadi 73 dan hasil peningkatan untuk Floor Push-up diperoleh peningkatan dari 45 menjadi 61,26. Yang berarti bahwa ada peningkatan yang signifikan pada program latihan. Maka dapat disimpulkan bahwa treatment Handstand Push-up lebih baik daripada treatment Floor Push-up untuk meningkatkan daya tahan otot lengan atlet gulat putra Jawa Tengah Tahun 2020 dengan membandingkan pre test dan post test.

\section{ABSTRACT}

This research is an experimental research. This research was conducted using quantitative descriptions and using "Two group pretest-posttest design". The subjects of this study were wrestling athletes of Central Java Province who trained at the Han Academy Solo Club, totaling 30 athletes, consisting of 15 athletes for Handstand Push-up treatment and 15 athletes for Floor Push-up treatment. Sources of data in this study came from 30 athletes. The data collection technique is through a push-up test to measure the endurance of the arm muscles. Data analysis used the Wilcoxon nonparametric statistical test. The results of data analysis can be presented as follows: The results of the increasing test for Handstand push-ups obtained an from 46,46 to 73 and the results of the increase for Floor Push-ups obtained an from 45 to 61,26. Which means that there is a significant improvement to the exercise program. So it can be concluded that the Handstand Push-up treatment is better than the Floor Push-up treatment to increase the endurance of the arm muscles of male 
wrestling athletes in Central Java in 2020 by comparing the pre

test and post test.

\section{Pendahuluan}

Olahraga merupakan kegiatan yang banyak disukai oleh manusia, banyak membawa manfaat bagi manusia. Beberapa di antara manfaat dari olahraga adalah menjaga kesehatan dan kebugaran tubuh, serta sebagai sarana rekreasi, sebagai sarana pendidikan dan sebagai ajang prestasi UU No. 3 tahun 2005 tentang sistem keolahragaan nasional. Dalam dewasa ini kesadaran masyarakat akan pentingnya melakukan kegiatan olahraga semakin meningkat, terbukti dengan diadakannya berbagai kegiatan olahraga yang memiliki tujuan sesuai dengan manfaat yang dihasilkan dari masing-masing kegiatan olahraga tersebut.

Di lingkungan masyarakat sudah banyak kegiatan olahraga dilakukan sebagai ajang prestasi meskipun secara tersirat bertujuan sebagai persahabatan dan mempererat persaudaraan. Hal tersebut tentunya sejalan dengan tujuan pemerintah untuk memasyarakatkan olahraga. Pemerintah sendiri dalam memasyarakatkan olahraga banyak menyelenggarakan ajang kompetisi olahraga resmi dalam berbagai tingkatan, mulai dari tingkat cabang, daerah, nasional hingga internasional. Berbagai cabang olahraga dipertandingkan dalam perlombaan resmi yang diselenggarakan pemerintah, di antaranya: sepak bola, bola voli, bola basket, atletik, renang, senam, beladiri dsb. Beladiri sendiri banyak macamnya seperti: pencak silat, karate, taekwondo, tarung drajat, kempo, gulat dsb.

Dari data permasalahan prestasi atlet putra gulat Jawa Tengah, gulat Jawa Tengah mengalami penurunan prestasi yang signifikan dari tahun 2008 pada saat PON di Kalimantan Timur atlet Jawa Tengah berhasil mendapatkan 2 medali emas dan 3 medali perunggu, pada PON berikutnya di Pekanbaru Riau 2012 atlet gulat Jawa Tengah hanya mendapatkan 1 medali perak dan 2 medali perunggu, dan yang selanjutnya di PON Jawa Barat 2016 kontingen gulat Jawa Tengah hanya mendapatkan 1 medali perak dari 4 atlet yang bertanding. Dan yang terakhir untuk PON Papua hanya 3 atlet gulat saja yang berhasil lolos babak kualifikasi PON Papua, 
ini menunjukan bahwa prestasi atlet gulat Jawa Tengah semakin menurun setiap tahunnya.

Gulat merupakan salah satu olahraga yang dilakukan oleh dua orang yang saling menjatuhkan/membanting, menguasai dan mengunci lawan dalam keadaan terlentang dengan menggunakan teknik yang benar sehingga tidak membahayakan keselamatan lawannya (Rubianto Hadi, 2007: 1). Gulat sendiri telah dikenal dan dipertandingkan sejak zaman Romawi yang dibawa ke Indonesia oleh tentara Belanda. Di mana pada zaman dulu masyarakat Indonesia mengenal gulat sebagai tontonan di pasar malam atau pada pesta-pesta dikota besar sebagai acara hiburan.

Gulat merupakan olahraga yang memerlukan dukungan daya ledak, kekuatan dinamis, dan isometrik, daya tahan aerobik dan aerobik, kecepatan, serta fleksibilitas (Andi Li-An Ho). Melihat pentingnya komponen kondisi fisik yang sangat berpengaruh terhadap kinerja atlet baik dalam latihan atau menghadapi pertandingan bagi seorang atlet gulat, kondisi fisik yang prima dapat dicapai dengan pembinaan yang tepat dan optimal. Pembinaan dalam hal ini meliputi pengembangan fisik, pengembangan mental, pengembangan teknik dan kematangan jiwa (M. Sajoto dan Sulistiono, 2015: 3). Pembinaan dilakukan untuk mencapai puncak prestasi target yang akan dicapai. Prestasi sebuah olahraga dalam hal ini adalah olahraga gulat tidak hanya mengandalkan penguasaan teknik, mental tetapi juga komponen fisik untuk menunjang kinerjanya dalam latihan dan juga pada saat menampilkan performa puncak dalam pertandingan. Agar proses latihan yang dipergunakan untuk meningkatkan kualitas fisik dapat juga dipergunakan untuk meningkatkan kualitas teknik dan taktik, maka perlu pengembangan metode latihan. Proses pengembangan metode latihan fisik harus memperhatikan komponenkomponen fisik. Keseluruhan komponen fisik tersebut harus selalu dilatih dan diukur secara berkala agar dapat diketahui peningkatan dan perkembangannya serta dapat dikaji penyebab apabila tidak ada peningkatan atau bahkan terjadi penurunan kondisi fisik. 
Pengertian daya tahan ditinjau dari kerja otot adalah kemampuan kerja otot atau sekelompok otot dalam jangka waktu yang tertentu, sedangkan pengertian daya tahan dari sistem energi adalah kemampuan kerja organ-organ tubuh dalam jangka waktu tertentu (Sukadiyanto, 2011: 60). Daya tahan merupakan komponen kunci pada sebagian besar cabang olahraga, termasuk menjadi salah satu komponen fisik yang sangat berpengaruh dalam cabang olahraga beladiri gulat. Level daya tahan yang baik akan menunjang kinerja atlet selama latihan dan juga bertanding. Dalam sebuah pergulatan seorang pegulat dituntut untuk tetap bugar untuk dapat berkonsetrasi menyerang ataupun bertahan. Jika level daya tahan menurun maka akan kesulitan memperoleh konsentrasi sehingga teknik, taktik dan juga mental tidak dapat dilakukan secara maksimal. Apabila demikian maka pencapaian prestasi atlet akan terhambat.

Daya tahan dalam komponen fisik digolongkan menjadi dua yaitu daya tahan umum yang merupakan daya tahan dari sistem kardiovaskuler dan daya tahan otot adalah daya tahan yang melibatkan beberapa kelompok otot dalam kinerjanya. Sedangkan berdasarkan tipenya daya tahan meliputi: daya tahan aerobik (dengan suplai O2) dan anaerobik (tanpa suplai O2 atau sedikit O2). Daya tahan berkaitan dengan durasi kinerja yang dilakukan dalam jangka waktu yang relatif lama. Dengan mengerahkan kinerja otot serta kemampuan kardiovaskuler, daya tahan yang dimiliki seseorang dapat ditingkatkan dengan latihan yang tepat sesuai dengan penggolongan setiap daya tahan itu sendiri. Dengan durasi kerja otot yang relatif lama maka dalam latihan daya tahan diperlukan energi untuk dapat melakukan metabolisme yang lebih besar sehingga cukup erat jika dikaitkan dengan lemak sebagai energi cadangan.

Meskipun daya tahan otot dalam kinerjanya hanya melibatkan sekelompok otot harus didukung adanya penyesuaian peredaran darah pada saat kontraksi agar suplai oksigen dapat memenuhi kebutuhan otot sehinga massa otot akan bertambah akibat dari terbentuknya jaringan-jaringan baru. Meskipun saling terhubung satu sama lain namun untuk mengukurnya biasanya dilakukan secara terpisah seperti 
untuk mengukur daya tahan otot lengan, mengukur daya tahan otot perut, mengukur daya tahan otot tungkai. Untuk mengukur daya tahan otot yaitu dengan tes push-up, caranya sampel mengambil posisi tengkurap kaki lurus ke belakang, tangan lurus terbuka selebar bahu. Turunkan badan sampai dada menyentuh matras atau lantai, kemudian dorong kembali ke atas sampai posisi semula (1 hitungan) lakukan sebanyak mungkin tanpa diselingi istirahat (Ismaryati 2008:123).

Daya tahan otot lengan sangat penting dalam keberhasilan teknik bantingan atas bagi pegulat, pasalnya sering kali dalam pertandingan atlet melakukan teknik bantingan atas yang tidak sempurna sehingga hanya menghasilkan point 2. Otot lengan terdiri dari otot lengan atas dan otot lengan bawah. Menurut Syarifudin (2006: 96-100), otot lengan atas terdiri dari otot- otot fleksor yaitu M. Bisep Braki, M. Brakialis, M. Korakobrakialis dan otot ekstensor yaitu M. Trisep Braki. Sedangkan otot lengan bawah terdiri dari otot ekstensor karpiradialis longus, ekstensor karpiradialis brevis, ekstensor karpi ulnaris, supinator, pronator teres, fleksor digitorum profundus, ekstensor digitorum. Teknik bantingan gulat sangat dipengaruhi oleh kualitas daya tahan otot lengan dari pegulat. Dengan mengembangkan metode latihan fisik, khususnya daya tahan otot lengan diharapkan dapat meningkatkan prestasi pegulat.

Melalui observasi yang dilakukan terdapat data bahwa atlet gulat Jawa Tengah diketahui pada saat bertanding sering kali mengalami kegagalan untuk mengambil teknik bantingan. Hal ini menyebabkan kerugian bagi atlet yang bersangkutan, bisa hanya mendapatkan point 2 atau bahkan hanya mendapatkan bantingan gagal atau 0 point. Dari permasalahan tersebut menurut data lapangan terdapat atlet dengan tipe daya tahan otot sedang dan kurang. Dalam kondisi ini diduga bahwa atlet-atlet gulat putra Jawa Tengah daya tahan otot lengan terdapat masalah yang dapat menghambat pencapaian prestasinya. Selain itu menurut pengamatan penulis bahwa dalam beberapa pertandingan banyak atlet gulat mengalami penurunan performa pada saat bertanding dan juga berlatih. Hal ini dapat diindikasikan bahwa pelatih kurang memberikan variasi dalam latihan, hal ini berdampak pada atlet itu sendiri merasa jenuh sehingga kurang maksimal dalam 
berlatih. Maka dari itu penulis akan memberikan perbandingan pengaruh variasi latihan yaitu Handstand push-up dan Floor push-up yang diharapkan dapat menjadi referensi variasi latihan bagi pelatih itu sendiri untuk meningkatkan daya tahan otot lengan atlet gulat putra Jawa Tengah tahun 2020.

Push-up adalah suatu jenis senam kekuatan yang berfungsi untuk menguatkan otot bisep maupun trisep. Posisi awal tidur tengkurap dengan tangan di sisi kanan kiri badan. Kemudian badan didorong ke atas dengan kekuatan tangan. Posisi kaki dan badan tetap lurus atau tegap. Setelah itu, badan diturunkan dengan tetap menjaga kondisi badan dan kaki tetap lurus. Badan turun tanpa menyentuh lantai atau tanah. Naik lagi dan dilakukan secara berulang.

Handstand push-up juga disebut push-up vertikal atau push-up terbalik yang juga disebut "commandos" adalah jenis latihan push-up di mana tubuh diposisikan di handstand. Untuk handstand yang sebenarnya, latihan dilakukan berdiri bebas, diadakan di udara.

Handstand merupakan sikap berdiri dengan kedua tangan, berarti kedua belah telapak tangan bertindak sebagai tumpuan. Beberapa gerakan yang dilakukan dalam Handstand yaitu mengayunkan kaki, melompat, mengangkat, dan mendorong. Keseimbangan dan kekuatan sangat diperlukan dalam melakukan Handstand.

Floor Push-Up adalah salah satu olahraga yang sangat mudah untuk dikerjakan dan tak memerlukan ruang yang lebar, Push-Up biasanya digunakan untuk membesarkan otot-otot tubuh, baik itu otot lengan, otot tangan, maupun otot perut. Push-Up bisa anda lakukan di atas matras, lapangan, lantai, ataupun ruang kecil dan floor push-up disini menggunakan lantai dan samsak sebagai tumpuan kaki.

Permasalahan daya tahan otot lengan atlet gulat putra Jawa Tengah ini menjadi kendala besar bagi pencapaian prestasi atlet gulat Jawa Tengah. Dilihat dari permasalahan tersebut disebabkan oleh daya tahan otot lengan atlet gulat Jawa Tengah yang sangat lemah atau kurang, dan tujuan peneliti menggunakan metode latihan handstand push-up dan floor push-up untuk meningkatkan daya tahan otot lengan atlet gulat putra Jawa Tengah, karena latihan push-up adalah metode latihan 
yang sangat baik untuk meningkatkan daya tahan otot lengan atlet gulat putra Jawa Tengah. Karena metode latihan push-up akan memperkuat otot halus pada otot lengan atlet gulat putra Jawa Tengah.

Berdasarkan beberapa permasalahan yang disampaikan di atas hal tersebut menjadi dasar penulis untuk meneliti peningkatan daya tahan otot lengan atlet gulat putra Jawa Tengah tahun 2020. Permasalahan pokok yang akan dibahas dalam penelitian ini yaitu :

1. Apakah ada pengaruh latihan handstand push-up terhadap daya tahan otot lengan atlet gulat putra Jawa Tengah tahun 2020?

2. Apakah ada pengaruh latihan floor push-up terhadap daya tahan otot lengan atlet putra gulat Jawa Tengah tahun 2020?

3. Apakah ada perbedaan pengaruh latihan handstand push-up dan floor push-up terhadap daya tahan otot lengan atlet putra gulat Jawa Tengah?

4. Manakah yang lebih baik latihan handstand push-up dan latihan floor push-up tehadap daya tahan otot lengan atlet putra gulat Jawa Tengah tahun 2020?

\section{Metode}

Metode penelitian yang digunakan adalah deskriptif kuantitatif dan menggunakan "two group pretest-posttest design" yaitu desain penelitian yang terdapat pretest sebelum diberi perlakuan. Dengan demikian dapat diketahui lebih akurat, karena dapat membandingkan dengan diadakan sebelum diberi perlakuan (Sugiyono, 2007: 64). Dengan latihan yang diberikan tersebut, akan terlihat hubungan sebab akibat sebagai pengaruh dari pelaksanaan latihan. Dalam penelitian ini penulis ingin mengetahui apakah ada pengaruh latihan handstand push-up dan latihan floor push-up terhadap peningkatan daya tahan otot lengan atlet gulat putra jawa tengah 2020 .

Penelitian ini dilaksanakan di Sasana Han Academy Jajar, Laweyan, Surakarta, Jawa tengah 57138 pada bulan oktober - november 2020 sebanyak 18 kali latihan dengan frekuensi tiga kali latihan dalam satu minggu, yaitu Senin, 
Rabu, dan Jumat jam 16.00 WIB. Pre Test dilakukan pada tanggal 19 oktober 2020 dan Post Test dilakukan Pada tanggal 16 November 2020.

Populasi seluruh atlet putra gulat jawa tengah 228 atlet ( data atlet yang aktif dan tercatat di koni jawa tengah di tahun 2019 ) dan yang aktif berlatih disasana han academy solo berjumlah 56 atlet. Sampel yang diambil adalah Atlet gulat putra Jawa Tengah berusia 15-39 tahun dan berlatih disasana Han Academy Solo dikarenakan Han Academy Solo memiliki jumlah atlet terbanyak di antara klub atau kabupaten/kota yang terdapat di provinsi jawa tengah yaitu sebanyak 30 atlet. Teknik pengambilan sampel penelitian menggunakan teknik sampling purposive. Sampling purposive adalah teknik penentuan sampel dengan pertimbangan tertentu. Teknik pengambilan sampel ini peneliti menggunakan seluruh populasi.

\section{Hasil dan Pembahasan}

Data hasil penelitian sebagai berikut:

Pencapaian tujuan yang diinginkan dalam penelitian ini dengan dilakukan tes daya tahan otot lengan dengan Push-up. Data yang dikumpulkan terdiri dari tes asal secara keseluruhan, kemudian dikelompokan menjadi dua kelompok, yaitu kelompok 1 metode latihan Handstand Push-up dan kelompok 2 metode latihan Floor Push-up, serta data tes akhir masing-masing kelompok. Data tersebut kemudian di analisis dengan statistik t-test seperti terlihat pada lampiran. Adapun rangkuman hasil analisis data secara keseluruhan akan disajikan dalam bentuk tabel sebagai berikut:

Tabel Deskripsi Data Tes Daya Tahan Otot Lengan Pada Atlet Gulat Putra Jawa

Tengah Tahun 2020

\begin{tabular}{|c|c|c|c|c|}
\hline Kelompok & Tes & N & Mean & Std \\
\hline Handstand Push-up & Awal & 15 & 46,46 & 9,560 \\
\hline & Akhir & 15 & 73 & 7,88 \\
\hline & Peningkatan & & 26,54 & \\
\hline Floor Push-up & Awal & 15 & 45 & 10,056 \\
\hline & Akhir & 15 & 61,26 & 5,612 \\
\hline
\end{tabular}




\begin{tabular}{|l|l|l|l|l|}
\hline & Peningkatan & & 16,26 & \\
\hline
\end{tabular}

Gambaran rata - rata tes awal dan akhir pada kelompok 1 dan 2 dapat dibuat diagram perbandingan sebagai berikut:

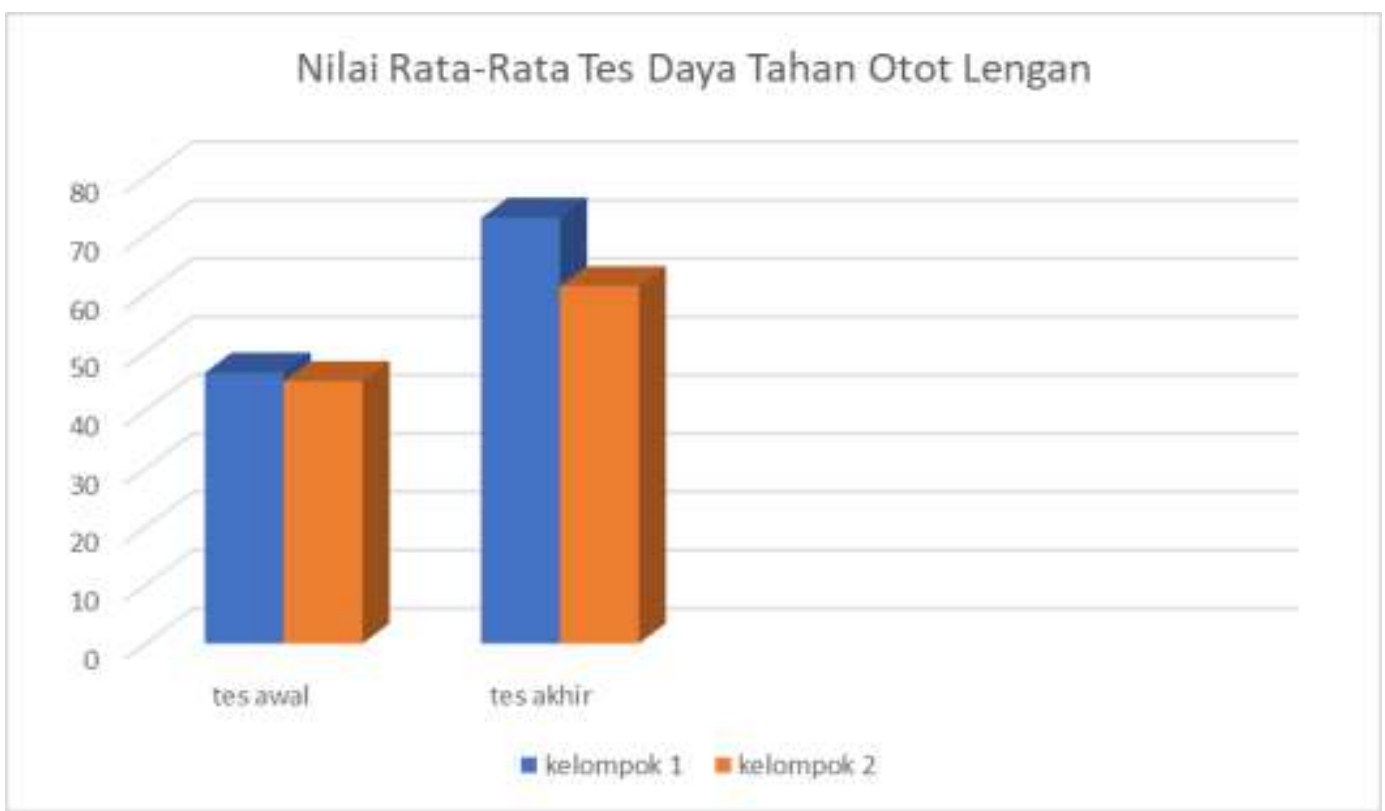

Gambar. Data Tes Awal Dan Akhir Kelompok 1 Dan 2

Kelompok perlakuan dengan Handstand Push-up dan kelompok perlakuan dengan Floor Push-up memberikan pengaruh berbeda terhadap daya tahan otot lengan atlet gulat putra Jawa Tengah Tahun 2020. Pada kelompok Handstand Push-up memiliki peningkatan sebesar 26,54, sedangkan pada Floor Push-up memiliki peningkatan sebesar 16,26.

\section{Pembahasan}

Berdasarkan hasil pre test dan post test dapat dilihat adanya pengaruh latihan Handstand Push-up dan Floor Push-up terhadap daya tahan otot lengan atlet gulat putra Jawa Tengah Tahun 2020 berdasarkan hasil pre test untuk handstsand push-up yaitu untuk nilai rata - rata sebesar 46,46 dan untuk hasil post test sebesar 73 dengan hasil prosentase peningkatan diperoleh nilai 57,69\% (Handstand Push-up) dan untuk nilai rata - rata pre test untuk floor push-up sebesar 45 dan untuk hasil post test sebesar 61,26 dengan hasil prosentase peningkatan sebesar 36,13\% (Floor Push-up). Berdasarkan data tersebut dapat disimpulkan bahwa terdapat pengaruh dalam latihan Handstand Push-up dan Floor Push-up.

Berdasarkan nilai prosentase peningkatan diketahui bahwa handstand push-up lebih baik dari floor push-up, dikarenakan beban yang didapat dari handstand push-up lebih berat 
untuk peningkatan daya tahan otot lengan atlet gulat putra Jawa Tengah Tahun 2020 karena berat badan bertumpu pada otot lengan.

Faktor utama yang mempengaruhi meningkatnya daya tahan otot lengan dengan Handstand Push-up dan Floor Push-up pada atlet gulat putra Jawa Tengah Tahun 2020 yaitu olahraga gulat adalah olahraga yang memerlukan daya tahan otot lengan yang sangat baik dan latihan daya tahan otot lengan yang sangat berguna untuk meningkatkan daya tahan otot lengan adalah dengan menggunakan metode latihan Handstand Push-up dan Floor pushup karena dengan latihan ini seseorang dapat mengetahui tingkat ketahanan daya tahan otot lengannya dengan menggunakan berat badannya.

\section{Simpulan}

Berdasarkan hasil penelitian dan analisis data yang telah dilakukan, dapat diambil kesimpulan sebagai berikut :

1) Terdapat pengaruh pada latihan handstand push-up dengan prosentase peningkatan sebesar $57,69 \%$ dengan nilai rata - rata pre test sebesar 46,46 dan post test sebesar 73 .

2) Terdapat pengaruh pada latihan floor push-up dengan prosentase peningkatan sebesar $36,13 \%$ dengan nilai rata - rata pre test sebesar 45 dan post test sebesar 61,26.

3) Terdapat perbedaan pengaruh hasil latihan Handstand Push-up dan Floor Push-up terhadap peningkatan daya tahan otot lengan atlet gulat putra Jawa Tengah tahun 2020 yaitu 57,69\% untuk handstand push-up dan 36,13\% untuk floor push-up.

4) Pada treatment Handstand Push-up lebih baik dibandingkan dengan Floor Push-up terhadap peningkatan daya tahan otot lengan atlet gulat putra Jawa Tengah tahun 2020. Prosentase peningkatan treatment Handstand Push-up didapatkan sebesar 57,69\% dan prosentase peningkatan treatment Floor Push-up didapatkan peningkatan sebesar 36,13\%.

\section{Ucapan Terima Kasih}

Penelitian ini digunakan untuk menghargai upaya rekan, yang tidak terdaftar sebagai rekan penulis, atas bantuan dan dana mereka untuk penelitian / publikasi Anda. Oleh karena itu, catatan standar 'pengakuan' biasanya diterbitkan di setiap artikel.

Karya-karya yang dikirim oleh penulis diakui tetapi direkomendasikan bahwa peninjau yang diputuskan oleh editor memberikan entri berharga ke setiap artikel untuk mempercepat pekerjaan peninjauan karena terbatasnya jumlah peninjau. Reviewer yang direkomendasikan dapat dicantumkan di halaman akhir setelah referensi karena review dilakukan dengan metode double-blind.

\section{Referensi}


Bill Welker. (2010). Buku Panduan Drill Gulat:100 Teknik Dan Taktik Drill. Sleman: KTSP (2006). Latihan Fisik Untuk Pembinaan Usia Muda. JORPRES (Vol.2.Nomor 1, Tahun 2006). Hal 78-91.

Bompa, Tudor O. 2011. Teori dan Metodelogi Latihan. Surabaya.

Efeklatihanfiiskotot.Online.http://www.hiithighintensityintervaltraining.ga/2016/12/efeklatihan-fisik-pada-sistem-otot.html (accesed 28/10/18)

FKIP UTP Surakarta. (2019). Pedoman Penulisan Skripsi. Surakarta: UTP Surakarta

Hartono. (2011). SPSS 16.0 Analisis Data Statistika dan Penelitian. Edisi ke 2, Cetakan ke 4. Yogyakarta: Pustaka Belajar.

Ismariyati. (2011). Tes Dan Pengukuran Olahraga. Surakarta: LPP UNS dan UNS Press

Juliansyah Noor. (2011). Metodologi Penelitian: Skripsi, Tesis, Disertasi, dan Karya Ilmiah. Jakarta: Kencana.

Kementrian Negara Pemuda dan Olahraga. (2005). Undang-Undang Keolahragaan Nasional No. 3 Tahun 2005. Jakarta.

Latihan daya tahan otot lengan. Online http:// walpaper hd 99. blogspot.com/2015/12/ bentuk - latihan - kekuatan - daya - tahan.html (accesed 15/10/2018) (https://olahragapedia.com/macam-macam-tes-kebugaran-jasmani)

Mark Mysnyk. (2010).Gerakan Dan Serangan Gulat Peraih Kemenangan.Sleman: KTSP

M. Sajoto. (1995). Peningkatan \& Pembinaan Kekuatan Kondisi Fisik Dalam Olahraga. Semarang: Dahara Prize Self Evaluation Kit

Pramudya Ananta Toer. (1995). Gulat Di Jakarta.Jakarta: Wira Karya.

Rubianto Hadi.( 2014). Buku Ajar Gulat. Semarang: Unnes Press.

Sugiyono. (2011). Metode Penelitian Kuantitatif Kualitatif dan R\&D.Bandung: Alfabeta.

Riduwan. (2007). Rumus dan Data dalam Aplikasi Statistika. Bandung: Alfabeta.

Suharsimi Arikunto. (2006). Prosedur Penelitian; Suatu Pendekatan Praktis.Jakarta: Rineka Cipta.

Suharsimi Arikunto. (2013). Prosedur Penelitian Suatu Pendekatan Praktik. Jakarta:Rineka Cipta. Online.

Sejarah gulat. Online http://ws-or.blogspot.com/2011/10/gulat.html (accesed 15/10/2019)

Sukadiyanto. (2011). Pengantar Teori Metodelogi Melatih Fisik. Bandung: Lubuk Agung. 